\title{
Smart Home Security through NFC
}

\author{
Abhishek, Anurag, Reji Thomas and Dr.B. Shadaksharappa
}

\begin{abstract}
Inspired by the "Smart India" initiative, here we present you with our own idea of a Smart Home for the Smart India. As of now most of the people forget their keys in a hurry but no one forgets his Smartphone. So why not to make the smartphone as your security network to control your door? So now the security network can be governed by an NFC present in your phone or by programming an NFC tag to control your smart lock. NFC is known as Near Field Communication but it is limited to a distance of $10 \mathrm{~cm}$ maximum for the device to act. So just you need is a Smartphone with NFC and control your door lock with it. It's very secure because NFC tags programmed to the lock can be ciphered and other than you no one can open it. If someone tries to open the lock with brute force the owner can be alarmed immediately.
\end{abstract}

Keywords--- Brute Force, Ciphered, Smartphone, NFC.

\section{INTRODUCTION}

$\mathrm{T}$ HIS paper presentation is mostly centralised toward the security of a home only, moving around the basic idea and its implementation. A separate section for advantages as well as disadvantages (if there) has been also given. To conclude with, we have also discussed some scenarios related to this technology, that may arise before or after its implementation.

Let's move towards the other part of my main title, the NFC. The most basic question that may arise here is: What is an NFC? Near field communication that means Contactless communication. It allows a user to surge the Smartphone over an NFC compatible device (RFID ENABLED) to sending formation without needing to touch the devices together or go through numerous steps setting up a connection. This ensures that NFC is secure and remains easy-to-use with various versions of the technology. Compatibility is the key to the growth of NFC as a popular payment and data transmission method. It must be able to communicate with other wireless technologies and be able to interact with various types of NFC transmissions. The technology behind NFC allows a device to create a radio frequency current that links with another NFC compatible device or a small NFC tag.

Abhishek, $2^{\text {nd }}$ Year, Computer Science and Engineering, Sri Sairam College of Engineering, Anekal, Bangalore, India. E-mail: abhishekbinay@gmail.com

Anurag, $2^{\text {nd }}$ Year, Computer Science and Engineering, Sri Sairam College of Engineering, Anekal, Bangalore, India. E-mail:as4195@gmail.com

Reji Thomas, Assistant Professor, Sri Sairam College of Engineering, Anekal, Bangalore, India.E-mail:rejitoms@gmail.com

Dr.B. Shadaksharappa, Professor, Computer Science and Engineering, Sri Sairam College of Engineering, Anekal, Bangalore, India. E-mail: hod.cse@sairamce.edu.in

DOI:10.9756/BIJSESC.8235

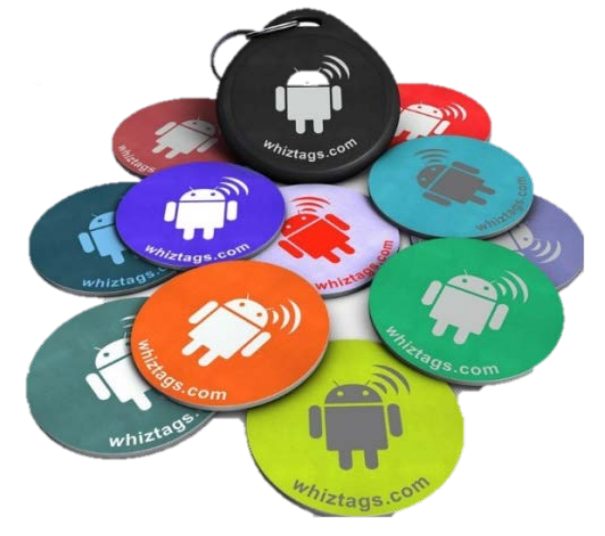

Peer-to-peer transmission is also possible through NFC [1]. This allows both devices to send and receive information.

Both businesses and individuals benefit from NFC technology. By integrating credit cards, subway tickets, and paper coupons all into one device, a customer can board a train, pay for groceries, recoup coupons or store loyalty points, and even exchange contact information all with the surge of a Smartphone. Faster transaction times mean less waiting in line and happier customers. Fewer physical cards to carry around means the customer is least bothered to lose one or have it stolen.

\section{The PROPOSITION}

Let's shift to the centre of my idea with a question: What are we in fact proposing?

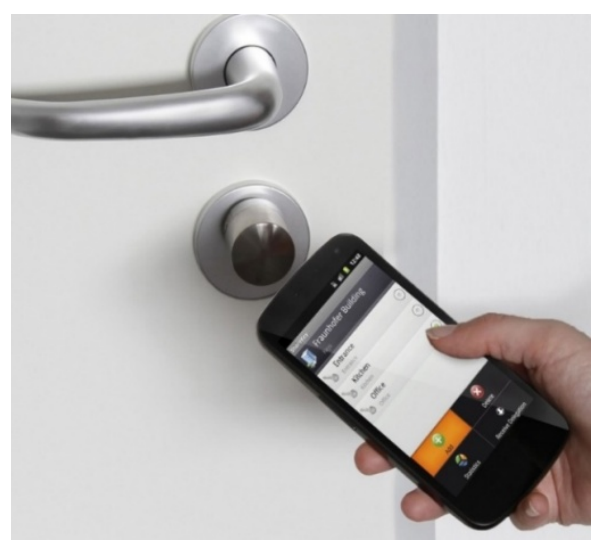

To assist the viewer, please refer to the picture.

We are primarily presenting here an idea for a smart door. The salient feature here is we don't want anyone to carry a key with them when they have a mobile phone to do the job. It's simple, just hover phone over the marked area, NFC inside a phone will send a unique signal to the NFC tag, the tag will verify the signal and then send a signal to open the lock and so 
the door will be unlocked automatically. And all that in just a fraction of seconds.

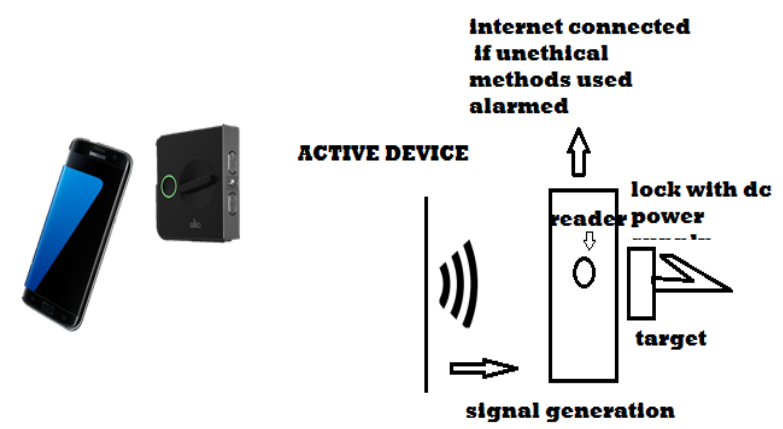

The best part of NFC tag is that it doesn't require any external power supply to operate. It gets all its energy from the field created in the course of the communication of the two devices.

\section{A. Why NFC and not QR Codes/ Barcodes?}

Another form of contact-less communication comes in the form of QR codes. QR codes are like barcodes. Yet NFC is more Programmable while $\mathrm{QR}$ codes remain the same once generated.

Usage of a QR code is decided depending on the programmed picture coded that links it to a particular task that is non-programmable. If we want to change the link, we must generate and reprint a new QR code.

The major impact in the market of NFC is its flexibility. Storing different types of information and changing it whenever you want to program it to a specific task is very easy and effective just by a single click. The owner can overwrite the information currently on the tag and create a new task to be performed [3].

The second major advantage of NFC is its ease of use. With a QR code, the user must open a scanner app on their Smartphone, hover over the QR code, and wait for the phone to analyse it and react to the code [3].

With NFC technology, the user waves the phone near the NFC tag area and the information is transferred instantly. No need to open an app or wait for analysis. The tag and reader communicate with each other to complete complex transactions quickly and securely [4].

\section{IMPLEMENTATION OF NFC DOORS}

Here comes the best part, and let me start with an initial question: How to implement this technology this technology in our homes? The good news here is that you don't need to buy a completely new door to use this. Just use this as an AddOn for your current door by expanding a reasonable amount of money for a single door.

Let's proceed to the constraints that may occur to enact this technology, discussed in the next section.

\section{A. Constraints}

Like any other technology these locks also have a few constraints that may occur while installation of NFC doors.

\section{Types of Locks}

The biggest constraint of this technology is that it could not be successfully implemented on all kinds of doors and especially not on the traditional Indian doors. In these doors, the mechanism to open them is too simple that even if we do install a mechanism to open these doors, it won't give the proper results expected and could be easily tempered. However, it's still good news that most of the new homes now a day doesn't have these locks. Rather we use a more advanced and complex lock for better security. So, this constraint can be eliminated.
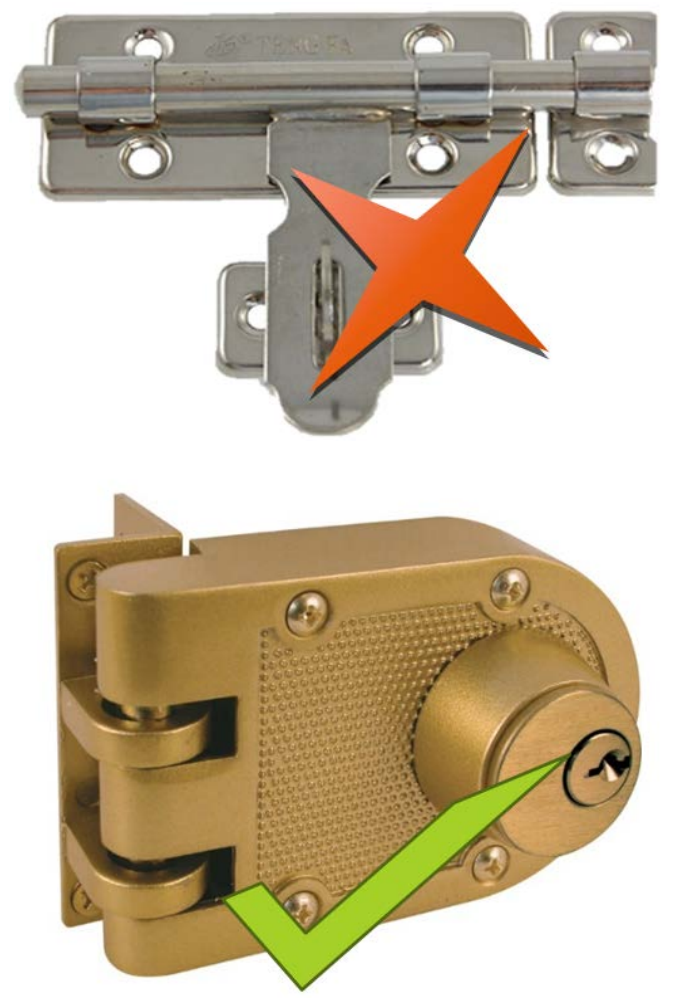

\section{Availability of NFC Enabled Phones}

Another problem that occurs here is in India, there are not many phones available with NFC support, due to the fact that NFC is not really popular here.

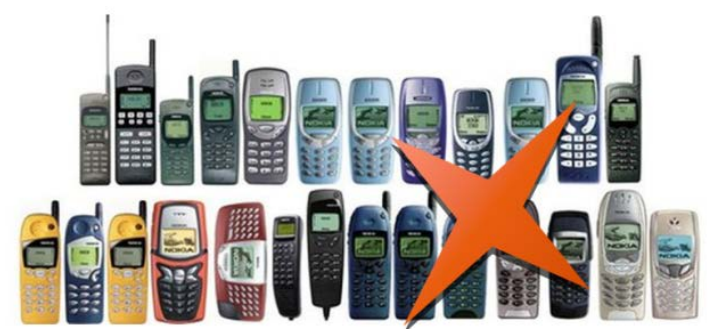

However, these days, every Smartphone company is launching new phones with NFC support. But even though if a phone does have an NFC support, its owner doesn't know about it at all. And why would he, he is not using it after all. NFC phones are there with a price bracket under 5000 rupees in the Indian market, but who is interested here in buying them. Everyone wants to buy an iPhone, but not for its features but because it's a status symbol. 


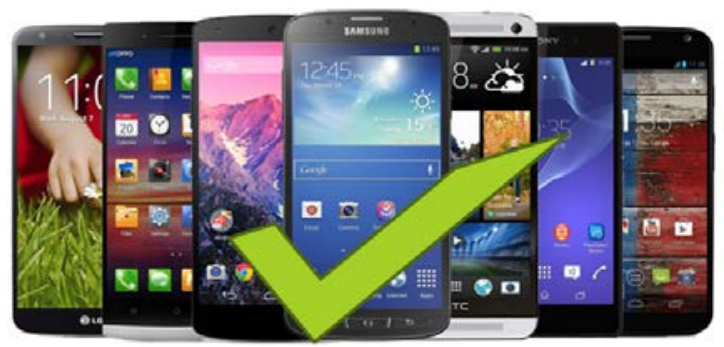

\section{AdVANTAgES AND DisAdVANTAgeS}

In this section, we will discuss the advantages or disadvantages associated with usage of this technology.

\section{Advantages}

- Contactless communication

- $\quad$ Fast and Convenient

- Very Secure

- Cheap

- Portable

- $\quad$ Lifetime of NFC tag - 5 years [2]

\section{Disadvantages}

- Not really popular among Indians

- $\quad$ Fewer phones with NFC support

\section{CONCLUSION AND FUTURE WORKS}

This technology can actually create a revolution in terms of security. NFC has a vast future, however, currently; this project is just in its initial stage. I am taking several scenarios that may occur if we actually install it, and yes there are some critical issues that also need a look. However, in future, if we do apply it in our practical day to day life, it can change the whole game.

In future, we will be able connect our home locks with our smart phones so as to provide a more interactive and secure interface to the user. Get an SMS every time someone enters through the main door. Expecting guests? Just link their ID to your account, so that they can also enter the house without any trouble. With face recognition system, it would take the security to the extreme level, so as to make sure that it's you and only you who are entering and not someone else who has stolen your phone, to enter the house.

\section{REFERENCES}

[1] http://nearfieldcommunication.org

[2] http://open-nfc.org/wp/home/features/

[3] C. Ortiz, Enrique, "An Introduction to Near-Field Communication and the Contactless Communication API”, 2006.

[4] T. Kasper, D. Carluccio and C. Paar, "An embedded system for practical security analysis of contactless smartcards", IFIP International Workshop on Information Security Theory and Practices, Springer Berlin Heidelberg, Pp. 150-160, 2007. 